\title{
PRODUCCIÓN DE BIOGÁS MEDIANTE FERMENTACIÓN LÍQUIDA DE LOS RESIDUOS SÓLIDOS DE PIÑA Y NARANJA
}

\section{BIOGAS PRODUCTION THROUGH LIQUID FERMENTATION OF SOLID WASTE OF PINEAPPLE AND ORANGE}

\author{
Vera-Loor José $^{1 *}$; Anchundia-Vélez Gema²; Sccipa-Mendoza María ${ }^{3}$ \\ ${ }^{1}$ Universidad Técnica de Manabí, UTM. Portoviejo, Ecuador. \\ ${ }^{2}$ Universidad Técnica de Manabí, UTM. Portoviejo, Ecuador. \\ ${ }^{3}$ Universidad Técnica de Manabí, UTM. Portoviejo, Ecuador.
}

*Correo: josveraloor@gmail.com

\begin{abstract}
Resumen
Este proyecto de investigación se enfoca en el estudio de una mezcla de los residuos de las cáscaras de frutas utilizando el microorganismo Escherichia Coli para su aprovechamiento en la digestión anaerobia en fermentación líquida. En el acondicionamiento y desarrollo experimental se tomaron a consideración parámetros como la concentración de materia orgánica, expresada como demanda química de oxígeno, temperatura, tiempo de retención y $\mathrm{pH}$. La velocidad de degradación está expresada como la producción de biogás bajo las diferentes condiciones. Los sustratos utilizados para esta investigación fueron los residuos de la cáscara de naranja y piña. El reactor que se utilizó en este estudio es un biorreactor de laboratorio que posee un sistema de control manual para los principales parámetros: temperatura, $\mathrm{pH}$ y agitación. Obtenidos estos resultados se prosigue con el diseño de un biodigestor anaerobio para la obtención de biogás. Se concluye que el tiempo de retención estimado para la producción de biogás de acuerdo al prototipo realizado es de 30 días, con lo que se garantiza la funcionalidad del diseño y la generación de los productos de la digestión anaerobia. Se recomienda la aplicación de este proyecto como una alternativa viable para el manejo adecuado de los residuos orgánicos y la protección del ambiente.
\end{abstract}

Palabras clave: biodigestor, digestión anaeróbica, residuos de frutas, Escherichia Coli, biogás.

\begin{abstract}
The present research project focuses on the study of a mixture of the residues of the fruit peels using the microorganism Escherichia Coli for its use in anaerobic digestion in liquid fermentation. In the conditioning and experimental development, a measurement of parameters such as the concentration of organic matter, expressed as chemical oxygen demand, temperature, retention time and $\mathrm{pH}$ will be taken. The degradation rate is expressed as the biogas production under the different conditions. The substrates used for this investigation were the residues of the orange and pineapple peel. The reactor specified in this study is a laboratory bioreactor that has a manual control system for the main parameters: temperature, $\mathrm{pH}$, and agitation. Once these results are obtained, the design of an anaerobic biodigester for obtaining biogas is continued. It is concluded that the estimated retention time for biogas production according to the prototype carried out is 30 days, thus guaranteeing the functionality of the design and generation of the anaerobic digestion products. The application of this project is recommended as a viable alternative for the proper management of organic waste and the protection of the environment.
\end{abstract}

Keywords: biodigester, anaerobic digestion, fruit residues, Escherichia Coli, biogas.

Información del manuscrito:

Fecha de recepción: 21 de marzo de 2019

Fecha de aceptación: 04 de junio de 2019

Fecha de publicación: 10 de julio de 2019 


\section{Introducción}

El proceso de digestión anaerobia para el aprovechamiento de la biomasa como fuente de energía renovable se ha aplicado desde el siglo pasado. Pero debido a que en épocas anteriores los problemas energéticos y ambientales no han sido tan drásticos como se presentan en la actualidad, su aplicación no había generado tanto interés. Sin embargo, frente al previsible agotamiento de las fuentes de energía fósil y al calentamiento global, es necesario buscar fuentes de energía alternas y renovables que paralelamente disminuyan la contaminación; por lo que se ha retomado el interés en la digestión anaerobia (Saval, 2012; Zhao et al., 2016).

El proceso de digestión anaerobia se lleva a cabo en un biodigestor, que es un recipiente herméticamente cerrado, el cual puede ser construido de diversas formas y materiales. En general, un biodigestor posee un ducto de entrada a través del cual se suministra la materia orgánica, un ducto de salida en el cual el material ya digerido por acción bacteriana abandona el biodigestor y un ducto en la parte superior por donde emerge el biogás producido (HolmNielsen et al., 2009).

Debido al aumento de los residuos sólidos urbanos, domésticos e industriales, la contaminación de los ecosistemas se convierte en un problema más grave, puesto que las soluciones tomadas hasta el momento no son viables. Los daños ambientales debido a los vertederos y a la incineración de desechos sólidos son graves, ya que contaminan el aire, las aguas subterráneas y superficiales, y el suelo. El humo proveniente de la quema abierta, así como los gases generados por la descomposición de desechos en un botadero abierto afectan la calidad del aire, debido a la emisión de distintos gases contaminantes como el monóxido de carbono, los óxidos de nitrógeno, el dióxido de azufre y los gases de invernadero (metano y dióxido de carbono) (Foresti et al., 2006).

Dichos gases se acumulan en la atmósfera, lo que ocasiona consecuencias negativas sobre la salud del ser humano, a la vez que afecta a todos los seres vivos y destruye los ecosistemas. De igual forma los lixiviados provenientes de los vertederos contaminan los suelos 
y las aguas superficiales y subterráneas, debido a la filtración de los líquidos contaminantes provenientes de la degradación de la materia orgánica (Corcoran et al., 2010).

Los sustratos utilizados son residuos de cáscaras de naranja y piña utilizando el microorganismo Escherichia Coli, ya que las bacterias son las encargadas de llevar a cabo la degradación de la materia orgánica. Por lo que el éxito del proceso de digestión anaerobia depende de cómo se aproveche este ecosistema bacteriano (Balu et al., 2012).

En este proceso intervienen una serie de parámetros que deben ser controlados para mantener un sistema estable con una alta producción de biogás y, por lo tanto, de energía. Dichos parámetros son: tipo de sustrato, $\mathrm{pH}$, temperatura, agitación, tiempo de retención y carga orgánica diaria. Los análisis que se deben realizar a la alimentación y a la mezcla reactiva para controlar y caracterizar el proceso son: demanda química de oxígeno, sólidos totales y sólidos totales orgánicos. Los productos que resultan de la digestión anaerobia son el biogás, que es un gas producido por las bacterias durante el proceso de biodegradación del material orgánico en condiciones anaeróbicas y un líquido conocido como biol que se utiliza como fertilizante orgánico (Amani et al., 2010).

Existe un gran consumo local, nacional e internacional de fruta ecuatoriana. Cada día las plantas procesadoras de alimentos crecen y con esto se incrementan significativamente los desechos generados. Actualmente, los residuos de las procesadoras de fruta no reciben ningún uso y su manejo es complicado, ya que deben ser recolectados frecuentemente para evitar la generación de olores y plagas. Encontrar una actividad productiva que haga de estos residuos una fuente de ingresos beneficia a las partes involucradas: productores y municipios encargados de la recolección y disposición final del desecho (Novillo, 2010). Por lo tanto, la reutilización de los desechos sólidos en la generación de una fuente de energía alterna y a la vez un abono que permita devolver al suelo la materia orgánica y los nutrientes que 
se extraen de él, se presenta como una solución favorable para este problema. En este sentido, la digestión anaerobia aporta potenciales ventajas; por lo tanto, la investigación tiene como objetivo, evaluar la productividad de biogás a partir de los residuos sólidos de las cáscaras de naranja y piña.

\section{Materiales y métodos}

\subsection{Diseño metodológico}

La experimentación fue desarrollada en un biodigestor batch a escala de laboratorio. En dicho biorreactor se introducen residuos de cáscaras de naranja y piña, empleando biomasa bacteriana Escherichia Coli en fermentación líquida para una proporción adecuada según la mezcla óptima. A continuación, se detalla la materia prima y los procedimientos que se llevan a cabo en la fase experimental.

La presente investigación constituye un estudio de tipo experimental, que permitió determinar el volumen de biogás y posteriormente realizar una comparación estadística de los rendimientos de biogás expresados en función de la productividad y su dependencia con variables de control como la temperatura, $\mathrm{pH}, \mathrm{y}$ tiempo de retención hidráulica.

La toma de datos se llevó a cabo de forma continua durante 26 días. Se realizaron pruebas para determinar la proporción óptima de la mezcla de sustratos, que fue alimentada junto la biomasa (E. Coli) en un biodigestor anaerobio vertical, el cual produce metano (biogás) y biol.

Este trabajo corresponde a un diseño de experimento puro. En función de lo mencionado por Gershenfeld (1999), este tipo de diseño experimental se fundamenta en la observación directa del fenómeno investigado, por consiguiente, se emplea esta técnica para la recolección de la información, así como también la observación interactiva y con participación y el diálogo explicativo, generando de esta forma mecanismos objetivos para la interpretación, discusión y verificación de los resultados obtenidos.

\subsection{Sustrato}

Los residuos de cáscara de naranja y piña se obtienen como subproducto del proceso doméstico e industrial de extracción de jugo en pequeños fragmentos, se obtuvo 1 
kilogramo $(\mathrm{kg})$ de cada muestra en una funda "ziploc" de $27 \mathrm{~cm} \times 28 \mathrm{~cm}$. En la producción de biogás las cáscaras de piña y naranja brindan la fuente de carbono.

\subsection{Biomasa}

La biomasa de E. Coli está integrada por bacilos Gram negativos no esporulados, aerobios-anaerobios facultativos. Fue obtenido del inóculo presente en la recepción de muestra en la Planta de Tratamiento de Aguas Residuales (PTAR) de la ciudad de Portoviejo, Manabí, Ecuador. Se realizaron análisis microbiológicos con la finalidad de reproducir los cultivos seleccionados de $E$. Coli en la muestra tomada en la planta de aguas residuales; estos fueron capaces de crecer en agar $\mathrm{EMB}$, por tanto, se resembró la muestra para purificarla y así obtener un inóculo de la bacteria. Posteriormente, fue vertida en caldo nutriente bilis verde, para finalmente durante un lapso de 72 horas a $37^{\circ} \mathrm{C}$, derivar el respectivo análisis de conteo de células bacterianas con la cámara de Neubauer que dio como resultado un número óptimo (6300 células de E. Coli) para iniciar con la inoculación en el reactor anaerobio.
Adicionalmente, se utilizó orina humana como fuente de urea $(80 \%$ del nitrógeno en la orina).

\subsection{Diseño del sistema}

El proceso de digestión de los residuos de cáscara de naranja y piña es anaerobio discontinuo, se consideró el proceso discontinuo debido a que la producción de cáscara de naranja y piña en algunos meses del año ocurre al pasar un día, y en otros meses del año ocurre de manera continua. Se tomaron en cuenta para el correcto funcionamiento del digestor anaerobio los siguientes parámetros operacionales: el tiempo de retención y temperatura, se seleccionaron de acuerdo a las recomendaciones de la bibliografía, el volumen total del digestor se determinó debido a la disponibilidad de un envase de vidrio, a partir de estos datos se consideró también el volumen de sólidos a procesar.

La carga diaria fue calculada a partir de la relación entre el volumen funcional $(1500 \mathrm{~mL})$ y el tiempo de retención (30 días). Por tanto, el volumen de la carga diaria fue 50 $\mathrm{mL}$; mientras tanto, el volumen inicial fue $300 \mathrm{~mL}$, según los datos que se presentan en la tabla 1. 
Tabla 1.

Características del sistema de digestión anaerobia de los residuos sólidos de naranja y piña

\begin{tabular}{ll}
\hline \multicolumn{1}{c}{ Parámetros } & Datos \\
\hline Tiempo de retención & 30 días \\
Temperatura & $18-35{ }^{\circ} \mathrm{C}$ \\
\% Sólidos & $8 \%$ \\
Volumen Total & $2000 \mathrm{~mL}$ \\
Volumen funcional & $75 \%$ \\
\% Inóculo bacteriano & $15 \%$ \\
\hline
\end{tabular}

\subsection{Biorreactor}

La construcción y adaptación de los accesorios del biodigestor se realizó en el laboratorio de Operaciones Unitarias de la Universidad Técnica de Manabí (UTM).

Se adaptó un recipiente de vidrio con una capacidad de $3000 \mathrm{~mL}$ que generalmente se lo utilizaba para el almacenamiento de líquidos. EI recipiente disponía de una entrada y no de salida. En la entrada, ubicada en la parte superior se colocó una manguera de $6 \mathrm{~mm}$ de diámetro y $150 \mathrm{~cm}$ de largo y para facilitar la salida de biogás se colocó una manguera de plástico, que desemboca en el recipiente de la solución alcalina de hidróxido de sodio, en un volumen de $2000 \mathrm{~mL}$.
Adicionalmente, se realizó un orificio en la parte superior del recipiente, introduciendo un difusor de suero que permitió, con la ayuda de una jeringa, extraer el biol del biodigestor para los análisis de control.

\subsection{Parámetros operacionales}

Se emplearon las condiciones experimentales, parámetros y procedimientos de medición que se explican a continuación. Los parámetros físicos, químicos y biológicos como demanda química de oxígeno, \% de sólidos.

\subsection{Implantación y control de parámetros operacionales}

\subsubsection{Control de fugas}

Previo al inicio de operaciones en el biorreactor se corroboró la existencia de fugas, para lo cual se llenó el biodigestor de agua de tal manera que se pueda evitar el escape de la mezcla (Amani et al., 2011). Para comprobar que el recipiente se encontrara totalmente hermético se introdujo aire a presión con ayuda de un compresor marca TRUPER, con lo que se verificó el cumplimiento de condiciones óptimas de operación. 


\subsubsection{Puesta en marcha}

Una vez adaptado el reactor batch, se agregó la mezcla de inóculo bacteriano de E. Coli, agua destilada, orina, residuos de cáscaras de naranja y piña alimentando al reactor con una carga de $1 \mathrm{~kg} \mathrm{DQO} / \mathrm{m}^{3}$ día hasta llegar a la carga orgánica máxima del reactor, se sella la tapa con silicón caliente y parafina para garantizar la hermeticidad. Se coloca el reactor en una temperatura ambiente y se controla que la temperatura de la mezcla se encuentre a 28 y $35^{\circ} \mathrm{C}$. La cantidad de biogás producido se mide diariamente mediante el desplazamiento de la botella invertida con agua.

\subsubsection{Monitoreo de biorreactor}

El pH de la mezcla debe mantenerse en el rango 6-8, por lo tanto, se empleó una solución tampón (carbonato de calcio), para regular el $\mathrm{pH}$ en caso de que la mezcla presente inconsistencias respecto a este parámetro. El pH fue medido mediante un potenciómetro. También se realizaron mediciones del potencial hidrógeno del efluente líquido, mediante la recolección del biol.
Como parámetro indicador de la concentración de materia orgánica o sustrato se utilizó la demanda química de oxígeno (DQO) en mg/L. Se determinó mediante el método colorimétrico que incluye el uso de un reactor $\mathrm{HACH}$ DRB 200 y un colorímetro $\mathrm{HACH}$ DR/890. El procedimiento implica que se prepare una solución de la muestra con agua destilada en una proporción 1:10; luego se tomaron $0,2 \mathrm{~mL}$ de la disolución preparada y se agregó un vial HR+ de la marca $\mathrm{HACH}$, agitando la mezcla durante 30 segundos y colocando el vial en el reactor en un período de 2 horas a $150^{\circ} \mathrm{C}$. La medición se realizó en el colorímetro, considerando que el resultado obtenido se multiplica por el factor 10 .

En cuando a la temperatura, se realizaron mediciones diarias con termómetro láser. Por otra parte, se verificó la producción de biogás mediante una jeringa plástica de 60 $\mathrm{mL}$, conectada a una manguera de descarga del elfuente gaseoso. Posteriormente, se transfieren 120 $\mathrm{mL}$ del biogás a una probeta que contiene solución de hidróxido de sodio al $4 \%$; esto con la finalidad de difundir el gas en la solución acuosa 
y generar la absorción del dióxido de carbono presente en el biogás en el medio acuoso; puesto que el desplazamiento provocado por el biogás corresponde específicamente a la presión del metano como único componente que no se disuelve ni absorbe en la solución alcalina. El volumen de solución desplazada de la probeta corresponde al volumen de metano. No obstante, se realizaron mediciones en el $\mathrm{pH}$ antes y después de la mencionada prueba, para detectar la absorción del $\mathrm{CO}_{2}$.
La relación entre el volumen de metano y el volumen de biogás corresponde a la composición porcentual de metano (v/v).

Las mediciones de $\mathrm{pH}$, temperatura y composición porcentual fueron realizadas dos veces por día.

\section{Resultados y discusión}

La figura 1 muestra los cambios de $\mathrm{pH}$ reportados durante la operación. Se observa que en los días 11 y 12 , el $\mathrm{pH}$ estuvo por debajo de los valores óptimos.

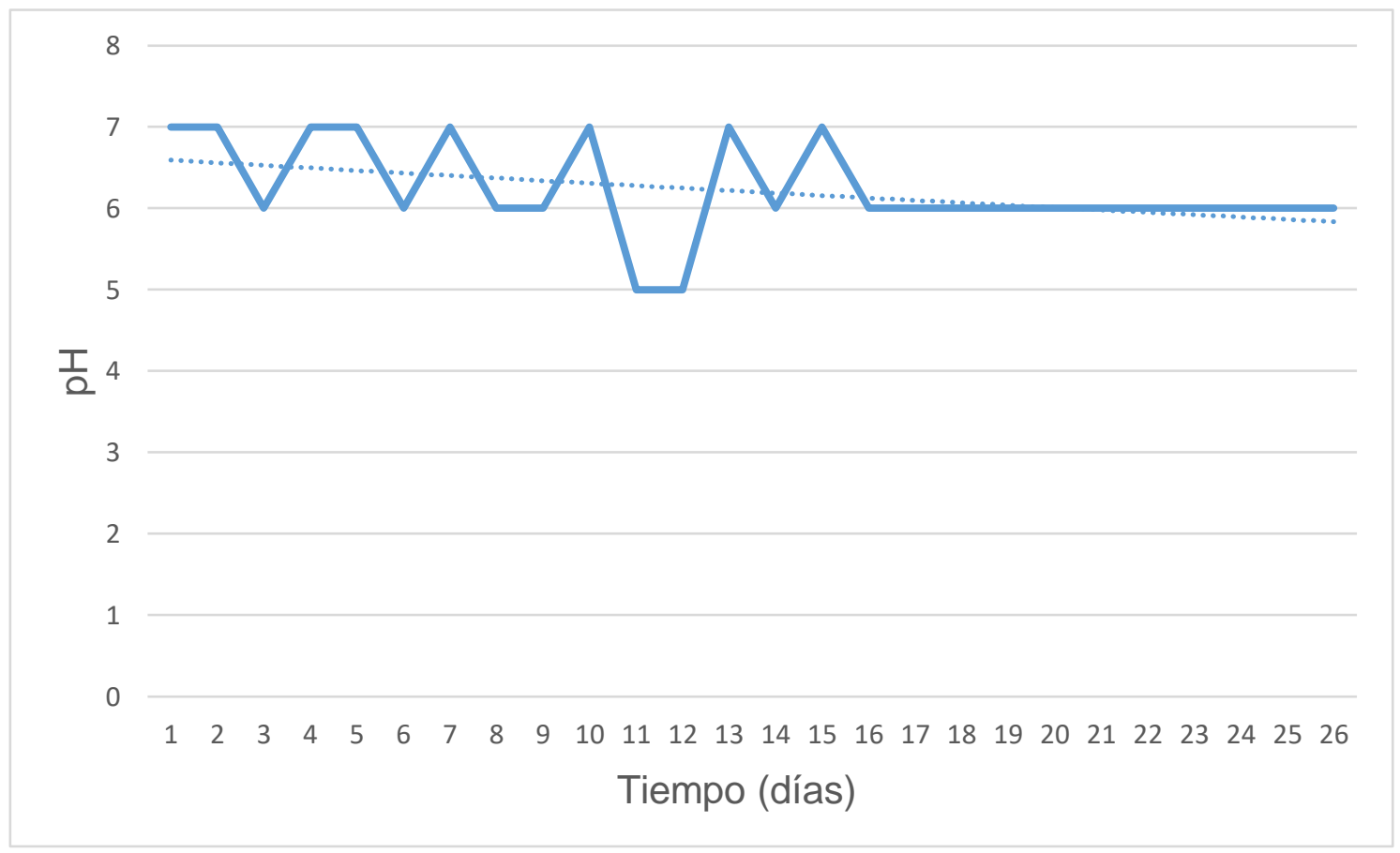

Figura 1. Monitoreo del pH en el desarrollo del de la digestión anaerobia

El biogás producido fue medido por el desplazamiento de solución alcalina $(\mathrm{NaOH})$ producto de la presión ejercida por el metano en el gas. La figura 2 refleja el volumen de solución acuosa desplazada durante 26 días. Se observa la estabilidad en el rendimiento de metano. 


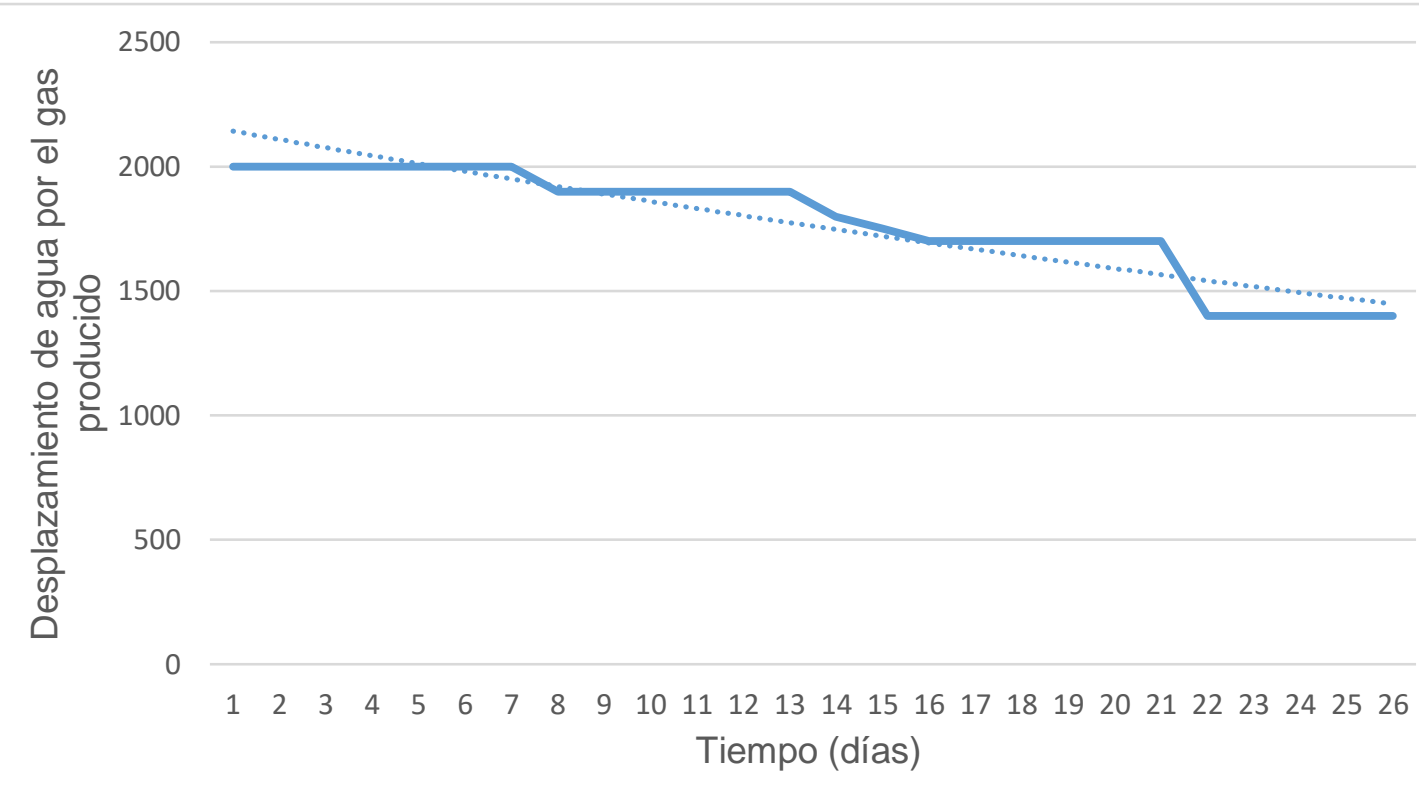

Figura 2. Monitoreo del desplazamiento de solución alcalina provocado por el gas

Se observó que la muestra de naranja presentaba un $\mathrm{pH}$ entre 5 a 7 , lo que obligó a tomar medidas en el pre tratamiento de la naranja, sin embargo, dentro del sistema de digestión anaerobia se controló el pH con una solución alcalina (carbonato de calcio) de pH 8. Según Demirbas \& Ozturk (2005) y Amani et al. (2011) en muchos casos, para mantener el pH óptimo en el reactor, es necesaria la suplementación de productos químicos alcalinos, tales como bicarbonato de sodio, carbonato de sodio, hidróxido de amonio, gas amoniaco, carbonato de calcio, hidróxido de sodio y potasio, entre otros.
Como se observa en las figuras 1 y 2 , se denota un comportamiento similar entre el flujo de producción de biogás y el $\mathrm{pH}$, lo que indica una relación directa entre ellos, ya que durante los días de disminución de $\mathrm{pH}$, también existió una disminución del flujo gaseoso y por lo tanto de la presión de salida del gas, esto se debe al estrés que sufren las bacterias y la muerte de algunas de ellas que requieren de un $\mathrm{pH}$ entre 6 y 8 para su desarrollo (Garcia-Peña et al., 2011), no obstante, es importante tomar en cuenta que a pesar de la disminución en la producción de gas nunca se llegó al nivel inicial, lo que indica que el sistema estaba totalmente 
estabilizado y funcionó de manera eficiente.

Cuando el biogás es de buena calidad origina una llama de color azul transparente sin emisión de males olores (Rizk et al., 2007). El biogás obtenido ha presentado estas características.

La producción de biogás está condicionada por cada una de las fases del proceso de digestión anaerobia, para Amani et al. (2011) es necesario considerar la formación de azufre y la utilización de agua para la degradación de la materia orgánica en fase de latencia.

Gracias a los microorganismos (m/o), especialmente la Escherichia Coli, se puede obtener gas metano en un sistema de digestión anaerobia, sin embargo, estos m/o son altamente susceptibles a los cambios en las condiciones ambientales (Garcia-Peña et al., 2011).

Se realizaron dos pruebas diferentes para determinar la calidad del gas producido. La primera prueba consistió en un análisis cualitativo de quemado, realizado cada vez que se extrajo gas del sistema. Con esta prueba se logró quemar el gas por sí solo, generando una llama de color azul, característica del metano. Por su parte, Garcia-Peña et al. (2011) afirman que los principales componentes del biogás son metano $\left(\mathrm{CH}_{4}\right)$ con $55-70 \%$ de concentración y dióxido de carbono $\left(\mathrm{CO}_{2}\right)$ con 35$40 \%$ de concentración.

\section{Conclusiones}

En este proyecto se investigó el proceso de biodigestión de residuos de cáscaras de naranja y piña en un biodigestor discontinuo. Se determinó que la mezcla compuesta por un $50 \%$ de cáscaras de naranjapiña, y $25 \%$ de microorganismo $E$. Coli permitió alcanzar rendimientos estables de biogás durante los 30 días de operación.

En el biodigestor se determinó que las cáscaras de naranja y piña se deben cortar en pedazos de $2 \mathrm{~cm}$ a $3 \mathrm{~cm}$, puesto que, por su alto contenido de fibra, las partículas de gran tamaño presentan dificultades para su descomposición biológica, ocasionando que se separen las fases sólida y líquida de la mezcla reactiva, además las fibras no permiten la agitación.

La mezcla reportada presentó rendimientos estables debido a que 
los niveles de acidez podían ser controlados, manteniendo dentro de los niveles de $\mathrm{pH}$ el rango óptimo, garantizando de esta forma, el cumplimiento de un requisito crítico en el crecimiento del microorganismo E. Coli.

\section{Bibliografía}

Amani, T., Nosrati, M., \& Sreekrishnan, T. R. (2010). Anaerobic digestion from the viewpoint of microbiological, chemical, and operational aspects-a review. Environmental Reviews, 18(NA), 255-278.

Balu, A. M., Budarin, V., Shuttleworth, P. S., Pfaltzgraff, L. A., Waldron, K., Luque, R., \& Clark, J. H. (2012). Valorisation of orange peel residues: waste to biochemicals and nanoporous materials. ChemSusChem, 5(9), 1694-1697.

Corcoran, E., Nellemann, C., Baker, E., Bos, R., Osborn, D., \& Savelli, H. (2010). Sick water?: the central role of wastewater management in sustainable development: a rapid response assessment (E. Corcoran, C. Nellemann, E. Baker, R. Bos, D. Osborn, \& H. Savelli Eds.). Arendal, Norway: UNEP/GRIDArendal.

Demirbas, A., \& Ozturk, T. (2005). Anaerobic digestion of agricultural solid residues. International Journal of Green Energy, 1(4), 483-494.

Foresti, E., Zaiat, M., and Vallero, M. (2006). Anaerobic Processes as the Core Technology for Sustainable Domestic Wastewater Treatment: Consolidated Applications, New Trends, Perspectives, and Challenges. Reviews in Environmental Science and Bio/Technology, 5(1), 3-19. Doi:10.1007/s11157-0054630-9

Garcia-Peña, E. I., Parameswaran, P., Kang, D. W., Canul-Chan, M., \& Krajmalnik-Brown, R. (2011). Anaerobic digestion and co-digestion processes of vegetable and fruit residues: process and microbial ecology. Bioresource Technology, 102(20), 94479455.

Gavilanes-Terán, I., Paredes, C., Pérez-Espinosa, A., Ángeles Bustamante, M., Gálvez-Sola, L., \& Jara-Samaniego, J. (2015). Opportunities and challenges of organic waste management from the agroindustrial sector in South America: Chimborazo province case Study. Communications in Soil Science and Plant Analysis, 46(sup1), 137-156.

Gershenfeld, N. (1999). The nature of mathematical modeling. Cambridge University Press: Cambridge. 
Holm-Nielsen, J. B., Al Seadi, T., \& Oleskowicz-Popiel, P. (2009). The future of anaerobic digestion and biogas utilization. Bioresource technology, 100(22), 54785484.

https://doi.org/10.1016/j.biorte ch.2008.12.046

Novillo, O. (2010). Desarrollo del Proceso de Producción de Biogás y Fertilizante Orgánico a partir de Mezclas de Desechos de Procesadoras de Frutas. Universidad San Francisco de Quito. Disponible en: http://repositorio.usfq.edu.ec/ bitstream/23000/741/1/96311. pdf
Rizk, M. C., Bergamasco, R., \& Tavares, C. R. G. (2007). Anaerobic co-digestion of fruit and vegetable waste and sewage sludge. International Journal of Chemical Reactor Engineering, 5(1).

Saval, S. (2012). Aprovechamiento de residuos agroindustriales: pasado, presente y futuro. BioTecnología, 16(2), 14-46.

Zhao, C., Yan, H., Liu, Y., Huang, Y., Zhang, R., Chen, C., \& Liu, G. (2016). Bio-energy conversion performance,

biodegradability, and kinetic analysis of different fruit residues during discontinuous anaerobic digestion. Waste management, 52, 295-301. 